\title{
TERRORISM AND RELATIONAL FRAME THEORY
}

\author{
Mark R. Dixon ${ }^{1}$ \\ Southern Illinois University \\ Simon Dymond \\ Anglia Polytechnic University, Cambridge, United Kingdom \\ Ruth Anne Rehfeldt \\ Southern Illinois University, United States of America \\ Bryan Roche \\ National University of Ireland, Maynooth. Ireland \\ Kimberly R. Zlomke \\ Southern Illinois University, United States of America
}

\begin{abstract}
The present paper presents a conceptualization of human behavior involved in terrorism from a Relational Frame Theory perspective. Relational frame theory is a contemporary behavior analytic account of human language and cognition. This account has yielded answers to many substantial empirical and theoretical psychological questions that have puzzled psychologists for some time. We believe that relational frame theory can and does account for the behavior of terrorists, those persons affected by terrorists acts directly and indirectly, as well as the entire culture of a country at large. This paper outlines the current state of psychological affairs regarding terrorism in the United States of America, traces the evolution and application of relational frame theory, and describes the prejudices that may follow from a terrorist attack or contribute to terrorist recruitment. Implications for scientists and practitioners are also presented.
\end{abstract}

Key words: relational frame theory, stimulus equivalence, transfer of function, terrorism, terrorists

The terrorist attacks on September $11^{\text {th }}, 2001$ have left a permanent scar on the United States of America. This scar runs much deeper than the destroyed buildings and the countless numbers of innocently lost lives. These terrorist attacks will remain as a reminder that the world is no longer a safe place to live, and that even the USA is vulnerable to catastrophic dangers from unknown persons from remote parts of the world. Many nations have lived with such a fear for centuries. Until now, the United States has not. The veil of security covering the USA population has been removed forever.

Many changes have taken place in USA as a result of the September $11^{\text {th }}$ attacks. They include new airline boarding policies, a nation-wide terrorist alert warning system, tightened patrolling of the nation's boarders, the creation of the

\footnotetext{
1 Authorship of this manuscript is equal. Authors are listed alphabetically. Address all correspondence to: Mark R. Dixon, Ph.D., Behavior Analysis and Therapy Program, Rehabilitation Institute, Southern Illinois University, Carbondale, IL 62901; email: mdixon@siu.edu.
} 
Department of Homeland Security, and a call for all United States citizens to report any suspicious behavior to local law enforcement. Cities now plan for terrorist strikes by running mock scenarios of chemical or biological warfare attacks. The US Postal Service now irradiates mail to political leaders, and warns its customers not to open any packages from unknown senders. Changes continue to occur in all aspects of US culture. One change that only recently to emerge is the psychological effects on our nation's population.

There has been an increase in persons across the country that are now seeking psychological services of clinicians for posttraumatic stress disorders related to September $11^{\text {th }}$ (Meisenhelder, 2002; Thobaben, 2002). Many United States citizens appear to have an increased need for human contact (Alper, 2002) and religious affiliation as a means of coping with such stress and devastation (Meisenhelder, 2002). Evidence also suggests that there was a $4.9 \%$ nation-wide rise in antidepressant prescriptions for 6 months following the attacks when compared to the 6 months prior to the attacks (Kettl \& Bixler, 2002). Case reports are still surfacing in the published literature of persons who have been more tempted to commit suicide now than before the attacks (Duggal, Berezkin, \& John, 2002). More American citizens now fear unknown persons of Middle Eastern descent. Indirect effects of changes to USA's psychological perceptions can also be found throughout many aspects of society, particularly within the MiddleEastern American community.

A report by the Council on American-Islamic relations (CAIR, 2002) has stated that over 60,000 Muslim-Americans have been negatively affected psychologically, and sometimes physically, following the September $11^{\text {th }}, 2001$ attacks. Their data include 1,200 Muslims singled out and detained by immigration officials and "treated as if they were terrorists." Other reports have documented 5,000 legal visa holders being asked to submit to "voluntary interrogations" (Deen, 2002). Other incidents of psychological distress include workplace discrimination whereby individuals were terminated or denied employment because of religious appearance; the refusal to accommodate religious practices in the workplace, schools, and prisons; the searching of individuals at airports because of their distinct names, appearances, and travel destination; the detention or interrogation of Muslims by federal and local authorities based on profiling criteria; and the denial of services or access to public accommodation facilities because of religious or ethnic identity (CAIR, 2002). Some 1,516 incidents of threats, discrimination, harassment and even physical attacks have been reported, while some 2,200 people were "targeted because of actual or perceived religion and ethnicity" (Swarthyguy, 2002). The fallout from the September $11^{\text {th }}$ attacks continues to impact the daily lives for persons of Middle Eastern descent within the United States in several ways; from suspicious glances, to cruel words and threats, to outright violence. The stage has been set for a war with an unfamiliar enemy whose most salient features are skin color and cultural practices unfamiliar to many Americans. The reasons why many United States citizens are stereotyping the average Middle Eastern American as a terrorist can be accounted for through a psychological theory entitled Relational Frame Theory (Hayes, Barnes-Holmes, and Roche, 
2001). This theory can also account for why persons from far away lands may come to hate the USA and its people when they have never even met a citizen of the United States.

\section{The Foundations of Relational Frame Theory}

Over the past 30 years, behavior analysts have begun to make serious scientific headway in the conceptual and empirical analysis of human language and cognition and their roles in a whole host of complex human behaviors, including prejudice and discrimination (see Hayes, Niccolls, Masuda, \& Rye, 2002; Roche, Barnes-Holmes, Barnes-Holmes, \& Hayes, 2001; Roche, Barnes-Holmes, BarnesHolmes, Stewart, \& O'Hora, 2002). The rapid acceleration of language and cognition research has been made possible by the identification of a phenomenon known as stimulus equivalence (Sidman, 1986) which has until relatively recently attracted sparse scientific attention within the behavioral sciences. In order to illustrate the stimulus equivalence phenomenon, we will outline a traditional laboratory procedure typically used to study this effect. Letters and numbers are used for illustration purposes to notate where different stimuli would be presented.

A participant is presented with a series of stimulus-matching tasks. For example, a sample stimulus (e.g., a Chinese character) is presented in the center of a table or computer screen, and two comparison stimuli are presented below it (e.g., nonsense syllables or abstract images). Let's call the sample stimulus A1 and the comparison stimuli B1 and B2, respectively. The participant's task is to choose between B1 and B2 conditional upon the sample stimulus. Feedback on performance is presented after each trial. The subject must choose B1 when A1 is the sample, but on another task choose the B2 comparison when A2 is the sample (we call this performance a conditional discrimination). Two further tasks are also presented in which either $\mathrm{A} 1$ or $\mathrm{A} 2$ is again presented as a sample, but in which two further stimuli, $\mathrm{C} 1$ and $\mathrm{C} 2$, are presented as comparisons. On these trials the subject must choose $\mathrm{C} 1$ when $\mathrm{A} 1$ is the sample, and choose $\mathrm{C} 2$ when $\mathrm{A} 2$ is the sample.

When the foregoing tasks are presented repeatedly, a participant becomes competent at performing the two conditional discriminations. That is, he or she can relate both $\mathrm{B} 1$ and $\mathrm{C} 1$ to $\mathrm{A} 1$ and both $\mathrm{B} 2$ and $\mathrm{C} 2$ to $\mathrm{A} 2$. What is particularly exciting, however, is that new relations then emerge between the stimuli without further feedback, reinforcement, or instructions (See Figure 1). More specifically, participants will spontaneously match $\mathrm{A} 1$ to $\mathrm{B} 1, \mathrm{~A} 1$ to $\mathrm{C} 1, \mathrm{~A} 2$ to $\mathrm{B} 2$, and $\mathrm{A} 2$ to $\mathrm{C} 2$ (i.e., reverse all the taught relations, or demonstrate symmetry) and derive new relations between the $\mathrm{B}$ and $\mathrm{C}$ stimuli (i.e., match $\mathrm{B} 1$ to $\mathrm{C} 1$ and $\mathrm{B} 2$ to $\mathrm{C} 2$, or demonstrate transitivity). When this occurs, the stimuli involved have formed derived equivalence relations (c.f., Sidman, 1986; see also Barnes, 1994; Fields, Adams, Verhave, \& Newman, 1990).Derived stimulus relations, such as stimulus equivalence, have proved very exciting to behavioral researchers because (a) their emergence is not predicted by traditional behavioral accounts, and (b) they appear to parallel many natural language phenomena. 


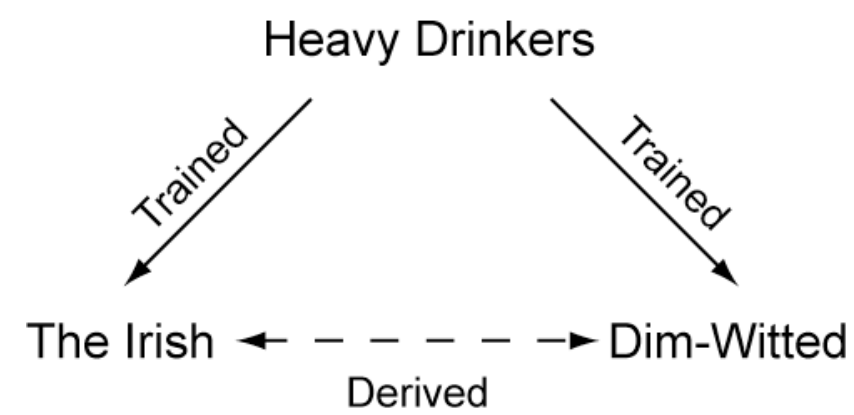

Figure 1. Equivalence relations trained and derived to result in the relation that "All Irish are dimwitted."

Another exciting feature of derived relations that is of particular importance in the context of prejudice is the derived transformation of functions. Specifically, if a behavioral function is established for one of the stimuli in an equivalence relation, the function of other related stimuli is transformed accordingly. For instance, if the $\mathrm{C} 1$ stimulus in the foregoing example is associated explicitly with a frightening stimulus, such as brief electric shock, then B1, but not B2, will also likely acquire fear-eliciting functions based on its derived equivalence relation to $\mathrm{C} 1$ (see Dougher, Augustson, Markham, Greenway, \& Wulfert, 1994; Roche \& Barnes, 1997; Roche, Barnes-Holmes, Smeets, Barnes-Holmes, \& McGeady, 2000, for relevant empirical evidence; see also Dymond \& Rehfeldt, 2000, for a review). We will consider the importance of this phenomenon for the analysis of prejudice and its prevention in subsequent sections. An important question to ask at this point, however, is where does the ability to derive stimulus relations come from?

\section{Relational Frame Theory}

Relational Frame Theory (RFT; Hayes, Barnes-Holmes, \& Roche, 2001) provides a functional-analytic account of the development of derived relational responding skills across the lifespan. According to RFT, the emergence of language and associated cognitive skills depends upon the establishment of an appropriate repertoire of derived relational responding by the social community (Barnes-Holmes \& Barnes-Holmes, 2000; see also Healy, Barnes-Holmes, \& Smeets, 2000; Lipkens, Hayes, \& Hayes, 1993). For example, in early language training children are exposed to object naming exercises in which teachers directly establish the skills necessary for derived relations to emerge between words, objects, and events. Children are often presented with objects and asked to say or repeat their names (e.g., "This is a ball. What is it?"). We can describe this interaction as; see Object A, hear Name B and say Name B. Children are also taught to orient toward objects when their names are stated (e.g., "Show me the ball"). We can describe this interaction as; hear Name B, then orient towards Object A. In early stages of language training each object-word and word-object relation is explicitly trained by the teacher. However, when a child has been 
provided with a sufficient history of relational training, generalized relational responding may emerge. That is, the child will eventually be able to produce a very wide variety of meaningful utterances with only a limited set of words and sounds. Suppose, for example, that a child with this history of naming is taught "This is your toy". Contextual cues (such as the word "is" and the context of the social interaction) predict that if this object is a "toy" (Object A, Name B), a "toy" is this object (Name B, Object A). Consequently, the child may now identify the object when asked "Where is your toy?" in the absence of prior training for doing so. Thus, RFT approaches derived relational responding as a type of generalized operant behavior (Barnes-Holmes \& Barnes-Holmes, 2000).

Once a basic repertoire of relational responding is established, it can be brought under increasingly subtle forms of contextual control. For instance, a young child may be easily taught to point to a ball from an array of three toys (e.g., Which one is the ball?"). In this case, the word "is" likely functions as the contextual cue that controls pointing to the ball object given the word "ball" (i.e., it specifies their equivalence). However, in time the child will also be exposed to more complex tasks in which the contextual cue is subtly changed to effect an entirely different response. For instance, a teacher may ask; "Which toy is bigger than the ball?" Now the phrase "is bigger than" functions as the contextual cue that controls the choice of a toy other than the ball. Through such concrete exercises sufficient contextual control may be established for phrases, such as "bigger than", "smaller than", "opposite to", and so on, that they too may become generalized and applicable to a wide variety of objects and events, some of which may bear relationships to each other which are entirely arbitrary and not identifiable form their formal features. As a specific case in point, most children learn to respond to a dime as "more than" a nickel, even though the formal features of the relata suggest the reverse (i.e., a dime is actually smaller than a nickel). When reliable patterns of relational responding come under the contextual control of environmental cues (e.g., the words "more than"), those patterns are referred to as relational frames.

A wide variety of studies have now been conducted that demonstrate the human ability to respond in accordance with relational frames, such as Sameness, Opposition, and Difference (Steele \& Hayes, 1991; Roche \& Barnes, 1996, 1997), More than and Less than (Dymond \& Barnes, 1995; O' Hora, Roche, BarnesHolmes, \& Smeets, 2002), and Before and After (O'Hora, Barnes-Holmes, Roche, \& Smeets, in press; see also Barnes \& Roche, 1996; Hayes \& Barnes, 1997).

The relevance of derived relational responding to the study of prejudice and its prevention has already been noted by RFT researchers (e.g., Hayes, et al., 2002; Roche, Barnes-Holmes, Barnes-Holmes, \& Hayes, 2001; see also Roche, BarnesHolmes, Barnes-Holmes, Stewart, \& O'Hora, 2002). Indeed it would appear that a greater scientific understanding of derived relations and the transformation of functions can extend considerably the traditional behavioral understanding of prejudice. For instance, Staats \& Staats (1958) found that a dislike of specific nationalities could be generated in the laboratory context by directly associating the names of those nationalities with unpleasant words. They asked participants to 
remember words paired with various nationality names, such as "German-table," "French-with," "Dutch-gift," and "Swedish-failure." For one group of participants, the target nationality "Dutch" was always followed by a word with a positive evaluative meaning, and the target nationality "Swedish" was always paired with negative words. This evaluative pairing was reversed for a second group of participants: "Dutch" was paired with negative words, and "Swedish" was followed by positive words. Each participant then rated on a Likert scale how they felt about the various nationality groups. The group that heard favorable word pairings with "Dutch" and negative pairings with "Swedish" had more positive attitudes toward the Dutch and less positive attitudes toward the Swedes. These ratings were reversed for the group that had opposite word pairings.

An analysis of nationality preferences in terms of derived stimulus relations, however, extends upon the Staats and Staats analysis by incorporating a further process by which words, and other events, such as faces, skin color, and names, might acquire aversive functions for an individual. More specifically, research into derived stimulus relations has suggested that an individual may not necessarily learn from peers, parents, teachers, or popular media that, for example, the Irish are a little 'dim-witted' in order to respond to the first Irish person they meet on this basis (cf. Roche et al., 2001). They might instead be told on one occasion that the Irish are a nation of heavy drinkers, and on another occasion that heavy drinkers are usually a little dim-witted. Based on what we know about the prevalence of derived relational responding in human language, these directly taught relations should suffice for the derivation of a relation of equivalence between the terms "Irish" and "dim-witted". Thus, while an unfounded prejudice against Irish people may not be directly taught by members of the wider community, it may effectively be established by modes of discourse concerning the Irish as a nation. As we shall see, Relational Frame Theory, as a theory and technology of language, provides the empirical and conceptual tools for the analysis of such modes of social discourse and their roles in the establishment, maintenance, and amelioration of prejudice and racial hatred.

\section{How Relational Frame Theory Can Explain the Formation of Prejudice, Racism, and Terrorism}

Relational frame theory may explain how many Americans have developed prejudices towards Middle Eastern persons who have no ties to the September $11^{\text {th }}$ terrorist attacks. Take for example a white American male who learns about the attacks on television early that Tuesday morning. He is watching the news, and finds out that someone has hijacked four planes, two were flown into the World Trade Center, one flown into the United States Pentagon, and one has crashed into a field in Pennsylvania. Using the previously described notion of stimuli and events, let us call the terrorist attacks themselves, "A". Immediately our white American male experiences feelings of rage. Let's call his emotional responses of rage and hate, "B". Reporters on the news claim that terrorists are responsible for these terrible acts, and depicts their pictures on the television set. Let's call the 
images of the terrorists, "C". Following from relational frame theory, the images of the terrorists themselves may now come to elicit feelings of hate or rage through a transfer of function across the stimuli in the newly created relational frame. As noted above, given A related to $\mathrm{B}$, and $\mathrm{A}$ related to $\mathrm{C}, \mathrm{B}$ will become related to $\mathrm{C}$. Now, when our white American male sees pictures of the suspected terrorists in the newspapers or on TV he may become rather emotional and possess feelings of hate. This should not come as a surprise. However, the relational network does not stop here.

The most salient features of the unknown terrorists are their race, religion, and country of origin and are described as such by the media. Specifically, the terrorists are Middle Eastern males, fighting a holy war against America, and they live in Afghanistan. Actual names of the terrorists may be provided, but are not attended to as easily as the other features. The generalization of feelings of hate and rage towards the terrorists begins to transfer to other persons sharing the same skin color, religion, and country of origin because of a formal similarity between them and the terrorists. Let's call the innocent members of a Middle Eastern descent, "D". The Middle Eastern man at the corner store "looks just like" the terrorists on television to our American male. The group of Muslims in town who go to church and pray every day "have the same faith" as those terrorists in Newsweek to our American male. The neighbor down the block is "from the same country" as the terrorists. He may now be considered suspicious to our American male. The formal properties of the $\mathrm{C}$ stimuli and the $\mathrm{D}$ stimuli now make these two, previously separate groups of people, approximately the same through stimulus generalization. Moreover, the feelings of hate and rage held by our American white male that were initially occasioned only by the terrorist attacks now have transferred beyond the terrorists themselves. They have transferred to innocent Middle Eastern persons. A racist has evolved from a once neutral young man.

A relational frame theory account can also explain the behavior of an unknown Middle Eastern male who comes to hate America and Americans so much so that he will die for that cause. Take for example a relatively young Middle Eastern male living in Afghanistan. At the age of 18 this young gentleman begins to struggle with how he will earn a living and make ends meet. Perhaps he just has learned that he will need to go hungry for the next few days because food is not available in his town. Let's call his current state of economic affairs and hunger, "A". Our young Middle Eastern male is outraged by his never ending struggle for food and money. Let's call this outrage, "B". Yet, who should our young man be outraged at? He can not be angry with his family or his fellow town's people for they are experiencing the same conditions that he is. However, one day upon a trip to the downtown area he overhears a group of other men speaking about how it is "America's fault" that there is no food. It is "America's fault" that everyone is so poor. And, "in America, everyone is fat, rich, and has swimming pools." Let's call these comments about America causing the depressed conditions in Afghanistan, "C". Now our young Middle Eastern male will transfer his emotional responses of outrage from " $\mathrm{A}$ " to "C", while never actually directly experiencing an American 


\section{DIXON ET AL.}

person or the country at large directly impacting his life. However, the relational network does not stop here.

Our young Middle Eastern male may also see that his new acquaintances in downtown appear not to be as bad off as himself. In fact they are eating food, have clean uniforms, and speak about the many virgins promised to them upon the completion of their holy war against America. Let's call this ideal state of affairs of the Taliban army, "Y". This ideal state of affairs is surely opposite to our young man's state of affairs, as mentioned before, "A". Also opposite of our young man's state of affairs is a feeling of happiness and pride in himself. Let's call these feelings, "Z". Now, through a similar transfer of stimulus functions, our young man begins to believe that feelings of happiness and pride are equivalent with joining the Taliban army. In notation, if $A$ is opposite of $Y$ and $A$ is opposite of $Z$, then $\mathrm{Y}$ is the same as $\mathrm{Z}$. A terrorist has evolved from a once neutral young man. While the two illustrated examples of relational frames depict an explanation of rather troublesome human behavior, more positive human behavior can evolve in the similar fashion.

\section{Using Relational Frame Theory to Help Eliminate Prejudice, Racism and Terrorism}

Traditionally, prejudice is thought to be extremely resistant to change, mainly because the processes that define it are so ubiquitous among human beings (Hayes et al, 2002; Roche et al., 2001, 2002). The verbal evaluative and categorical processes that underlie prejudice and the perpetration of acts of terror based upon it are core features of the generative nature of human language and cognition. A member of Islamic Jihad, for instance, need not directly experience martyrdom for that outcome to be reinforcing. It is enough that the act of martyrdom itself participates in a whole host of relations with other verbal events, self-statements, and derived consequences (e.g., "to die now and become a martyr would be the supreme act of allegiance to the word of Allah and help to defeat the infidels;" see also, Hayes, 1992). In this analysis, prejudice and terror acts involve a derived transformation of the functions of certain individuals or groups based on oftenindirect contact with a few members of the prejudiced group (Roche et al., 2001, 2002). Cultural interventions aimed at reducing prejudice can maximize what is known about these derived processes and seek to re-inform attitudes and opinions.

In general, media-driven and common sense educational approaches to reducing prejudice will always fail for several reasons. First, educational instructions about the prejudiced group usually refer to group membership and thus may paradoxically help to increase group membership. In other words, the instructions "don't believe that all Muslims are terrorists" (See Figure 2) functions to increase the salience of "Muslims" as a categorical concept and adds features to the category. Noticing this process is relatively easy when a novel group is involved. For instance, consider the statement "don't believe that all tall sumowrestlers are bad, they are excellent cooks". This statement may form a category of 


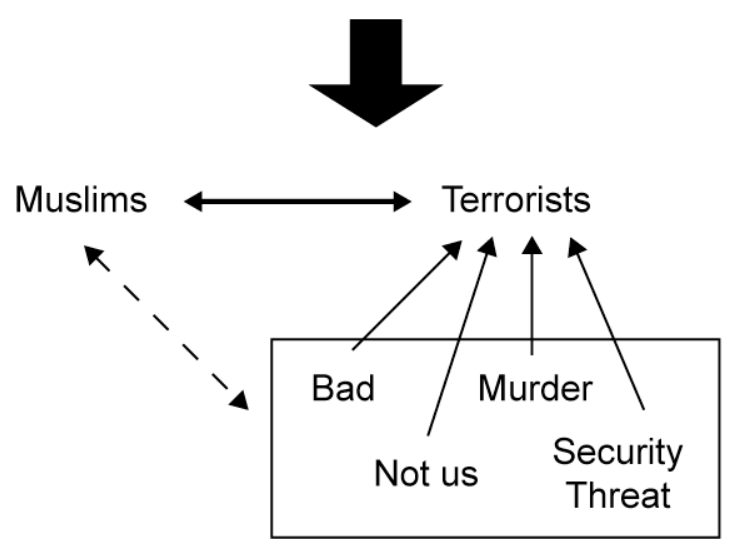

Figure 2. RFT depiction of how the instruction, "Don't believe all Muslims are terrorists" can add features to the category of Muslims.

"tall sumo-wrestlers" that had never been formed before, and hence verbally attribute features to the entire group (i.e., "excellent cooks").

The second reason that common sense educational approaches are doomed to failure is that educational instructions aimed at reducing prejudice may actually strengthen stereotypes via derived relational responding. Denouncing stereotypical views only serves to actualize some of the prejudicial functions because, by definition, common stereotypes are readily available in the verbal repertoire of most members of a culture. Hence, one stimulus (e.g., "West Bank") will likely prime another (e.g., "Gaza Strip") whether or not someone is explicitly taught to form this relation (see Fazio, 2001, for a review of affective priming).

The final reason anti-prejudice education may fail is that it may serve to increase the aversiveness of groups by adding negative functions to already established prejudiced thoughts. The vast literature on thought suppression demonstrates that efforts at suppressing the frequency of intrusive (prejudicial) thoughts, although initially successful, will lead to a cumulative increase in the frequency and behavioral impact of the intrusive thoughts over the long-term (see Purdon, 1999; Wegner, Schneider, Carter, \& White, 1987). Hence, the less willing you are to have an unwanted thought about a prejudiced group, the more likely it is that you will have it.

Consider, for instance, the instruction "It is sad to think that Hamas are intent on destroying the state of Israel." This instruction is likely to not only increase the salience of the group Hamas as an entity in its own right, but it also specifies that the one should avoid thinking of Hamas and its aims. As suggested above, this common-sense strategy used by people wishing not to feel sad about the current state of terrorism in the world may well increase the frequency of the unwanted, prejudiced thought, and to an avoidance of situations that might give rise to it 


\section{DIXON ET AL.}

(such as news coverage and even progressive discussions of the Middle East peace process).

The paradoxical effect of common sense attempts to deal with prejudicial thoughts has been demonstrated in a wide-variety of studies (e.g., Purdon, 1999; Macrae, Bodenhausen, Milne, \& Jetten, 1994; Smart \& Wegner, 1999; Wegner, 1994) and is readily predicted by RFT (Wilson, Hayes, Gregg, \& Zettle, 2001). Specifically, thought suppression involves an active search for, and rehearsal of, thoughts other than the thought to-be-suppressed. According to one researcher, once a prejudiced thought is suppressed, "more and more stimuli become relevant to the thought, and serve as cues for it. These cues are readily detected....and, through their association with the target thought, actually evoke it. Thus, the very processes used in the service of suppression work to elicit the thought" (Purdon, 1999, p. 1030).

According to RFT, the failure of thought suppression works as follows. When an individual has, for instance, the thought, "I must not think of Muslims as bad", a bi-directional relation is established between "Muslims" and "bad". The relational quality of human language and cognition means that these events (i.e., "Muslim" and "bad") acquire the functions of each other. Thus, the avoidance effort actually strengthens the relation between the two events and the transformation of their functions (i.e., Muslims may become more and more bad each time the thought is rehearsed). This problem highlights that verbal relations about prejudice will only be further strengthened and elaborated by any direct attempt to undermine them.

\section{Cultural Interventions Based on RFT}

A more effective method of reducing prejudice may be to create contexts that reduce the psychological importance of categorization per se. For instance, inducing a context of relaxation has been shown to influence the ability of clinically-anxious persons to form verbal relations involving terms or phrases that might otherwise be difficult for them (e.g., a relation between anxiety-provoking words and more positive words; see Burns, 2001; Leslie, Tierney, Robinson, Keenan, Watt, \& Barnes, 1993). This dilution of some of the functions of verbal relations through relaxation makes it more likely that new verbal relations will be formed even when those relations conflict with older stereotypes (e.g., thinking of a Northern-Irish Catholic politician playing a Protestant Lambeg drum; see Watt, Keenan, Barnes, \& Cairns, 1991). The foregoing suggests that it may be possible to change the very context in which verbal relations are formed, and in this way to loosen up rigid verbal relations that characterize stereotypes and prejudices. One study by Clayton (1995) attempted to do just this within a human service organization. This study was concerned with identifying and changing beliefs commonly held by staff about their work environment. Staff who believed that the work environment was "chaotic" showed greater attitude change when their previously identified positive attributes about the organization were linked to existing negative beliefs in a persuasive speech made by the director of the organization. Specifically, the speech intervention related negative attributes (e.g., 


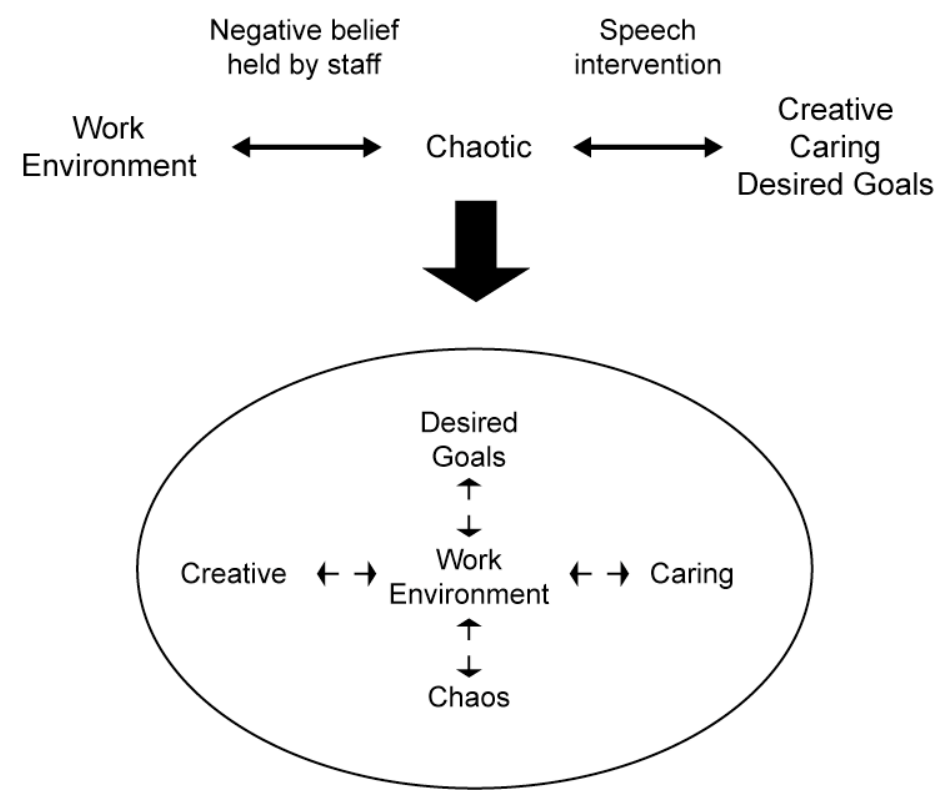

Figure 3. How adding elements to an existing verbal network through a verbal intervention can change thinking and behavior.

"chaotic") to desired attributes such as "creative" and "caring" and described how the employees can help move towards these desired goals. In effect, the positive functions of events identified by the employees transformed the functions of the negative events to which they became related (See Figure 3). Thus, it emerged that adding elements to an existing verbal network in an attempt to change thinking and behavior is much easier than building up a set of new verbal relations (i.e., ways of thinking and talking).

Another effective method of preventing prejudice may be to reduce the likelihood of unwanted derived transformations of functions occurring in the first instance. One way in which this can be achieved is through the use of mindfulness interventions, in which people are taught to "stand back from", or to" just notice" prejudicial thoughts without reacting to or evaluating them (Hayes et al., 1999). When an individual is mindful of a stereotype, watching it without evaluating it, the context for the transformation of functions is extremely broad. For instance, the individual is not trying to avoid the thought, think of its opposite, judge how bad or good it makes them feel, compare it to other stereotypes, and so on. Thus, the number of ways in which its functions might transform is myriad. Indeed, what appears to happen in mindfulness exercises is that the functions of all events that come to mind, both positive and negative, can together help to transform the functions of the stereotype such that the individual's opinion of the stereotype broadens enormously (See Figure 4). For example, in addition to negative stereotypical thoughts, the person in question may now also have thoughts relating to the diet of Muslims, the typical climates they live in, the Arabic word for televi- 


\section{DIXON ET AL.}

\section{Mindfulness Intervention}

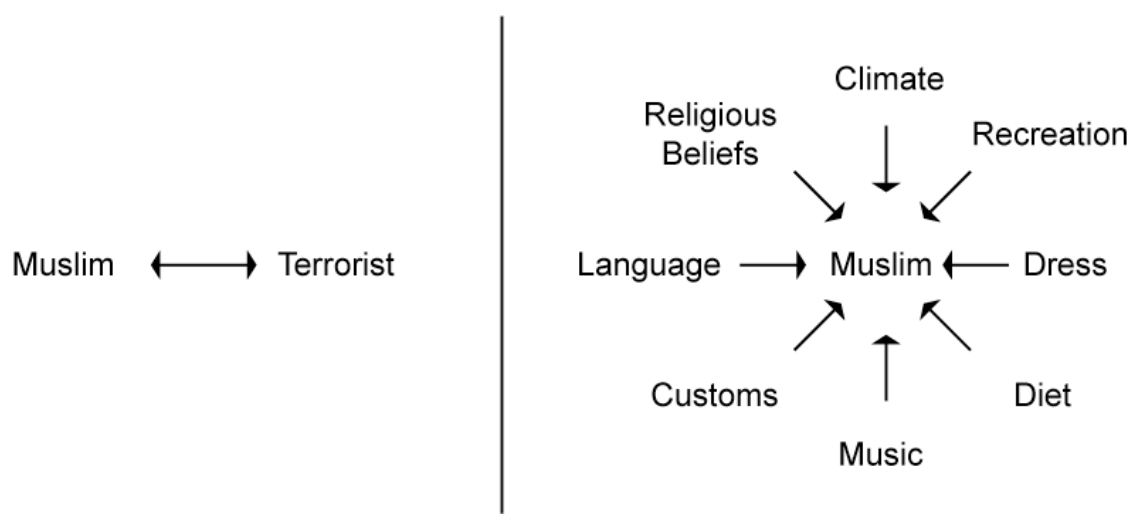

Figure 4. Example of a mindfulness intervention transforming the functions of a stereotype such that the individual's opinion of the stereotype broadens.

sion, and so on. Thus, a context of mindfulness can "dilute" the transformation of functions effect by increasing the number of functions that come to bear when the individual next thinks of Muslims. The mindfulness approach has proven successful in reducing prejudicial attitudes and behavior towards the physically disabled (Langer, Bashner, \& Chaowitz, 1985). What we need now, however, is further research to investigate the potential of mindfulness techniques for use with large groups of individuals.

Closely related to mindfulness is another therapy-based technique known as deliteralization (Hayes et al., 1999). Deliteralization involves the repetition of negative terms or statements until they become meaningless and nothing more than a series of sounds (the reader can try this by repeating the word 'Hamas' as fast as possible 100 times). Deliteralization, has been successfully used in the treatment of paraphilias (LoPiccolo, 1994) and appears to work by stripping away the layers of meaning that are attached to each and every word in the human lexicon. In this way emotive terms related to prejudice and terrorism, such as " $9 / 11$," "al Qaeda," and "axis of evil," among others, can have their potent meanings dramatically reduced through systematic repetition. Consequently, reflex reactions towards aggressors are less likely to occur. This technique may be familiar to many readers as that used by gay rights activists by the proliferation of the term "queer" in order to strip away its negative functions.

Perhaps one obvious way of ameliorating prejudice is to facilitate direct contact with members of prejudiced groups through cooperation. Community interventions targeting children and adolescents from stigmatized groups can be extremely effective in reducing prejudicial attitudes towards these groups (Desforges, Lord, Ramsey, Mason, Van Leeuwen, \& Lepper, 1991). In one famous example by Sherif, Harvey, White, Hood, William, \& Sherif (1961; see also Sherif, 1956), a three-phase field study was conducted with twenty, 11- to 12-year old boys at a specially created summer camp. In the first phase, two in-groups were 
created in which each group of boys separately engaged in recreational tasks and developed their own leaders and unique social identity (the "Rattlers" and the "Eagles"). During the second phase, Sherif examined whether inter-group competition would cause prejudice by having the Rattlers and the Eagles compete against each other in a weeklong athletics tournament. Sherif noted that friendships were of the in-group variety and inter-group hostility, as manipulated through competition, lead to an increase in in-group solidarity and negative attitudes towards the out-group. In the final phase of the study, the idea was to reverse the inter-group hostility by arranging simple non-competitive contact between the groups. Following a co-operative effort at re-instating the camp's water supply and rescuing the camp bus, the negative out-group stereotypes declined and out-group friendships soon flourished. This study illustrates that not only is inter-group hostility established through competition, but that prejudice and stereotypes can be reduced by arranging direct, co-operative contact between groups on some mutually-shared goal.

According to RFT, the direct contact between groups increases the number of functions attached to each group member and massively expands the transformation of functions. In effect, "terrorist" is then not the only function that comes to mind when someone hears the word "Muslim," or "infidel" is not the first thing that comes to mind when someone else hears the word "American."

One important aspect of this varied contact with the outside or feared group is that it forces the formation of multiple, hierarchical, and overlapping categories concerning out-group members. That is, instead of merely describing someone as a "terrorist", it is more likely that a composite picture of an individual in terms of being a son/daughter, husband/wife, worker, teacher, or priest will reduce prejudice and instead shift the focus to the religious or political motivation behind them being considered a "terrorist" in the first place (see Taylor, 1988).

\section{The Research and Political Agendas that Lie Ahead}

In order to further our understanding of the role of relational responding in the formation of cultural biases and prejudices, a number of potential research questions come to light. Indeed, in order for wide scale interventions designed to reduce stereotypes and misunderstandings of other cultures to be successfully implemented, a strong research foundation illustrating the processes involved is imperative. It is hoped that these suggestions will inspire behavioral scientists to launch research programs that will address these issues. However, it will take more than occasional, scattered studies here and there to provide the necessary foundation on which a technology of behavior change can be based. University labs must make this the focus of their research pursuits. Collaboration between labs will be necessary. Graduate students in the behavioral sciences must learn the behavioral processes underlying cultural stereotypes as a regular part of their educational curriculum. Journal editors must make explicit efforts to publish manuscripts on these topics. Finally, as our knowledge base builds, federal grant programs must make it a priority to fund research programs that address these 
issues. What follows are suggested themes on which basic laboratory, applied clinical, and applied community projects might focus.

A preliminary foundation for the role of derived stimulus relations in Americans' attitudes towards terrorism was established by Dixon, Rehfeldt, and Zlomke (under review), and Dixon, Zlomke, and Rehfeldt (under review), whose results showed slower acquisition and reduced likelihood of equivalence class formation when the relata were American and terrorist images. However, it was possible for subjects to nonetheless acquire derived relations between those stimuli. Future research should focus on replicating these results. Several other research questions can also be addressed using this same procedure. The extent to which derived stimulus relations promoting cultural stereotypes can be established on the basis of observation merits investigation. Children often acquire stereotype views from growing up in a household or region where such views are frequently expressed. As such, a direct history of reinforced relational responding may not be necessary for a child to demonstrate derived stimulus relations, but simply observing another individual demonstrate the stimulus relations may be sufficient. A Middle Eastern child may grow up observing the reinforcement of his father's descriptions of Americans as evil, greedy, power monger who should be suppressed. The child may then derive relations accordingly-power mongers are Americans, to be evil is to be an American, and the like. Recent research has shown that children can derive relations of sameness after simply observing other children be reinforced for making the baseline conditional discriminations (Rehfeldt, Latimore, \& Stromer, in press). In future research, subjects might be required to observe others receive reinforcement for conditionally relating negative words and cultural emblems, and then be tested to determine whether they, in fact, derived relations between those words and the cultural emblems simply on the basis of observation. If so, observational learning may provide a powerful explanation for how cultural stereotypes based on derived stimulus relations become so pervasive.

Another important area of investigation concerns the generalization of derived stimulus relations to novel stimuli that are physically similar along some dimension to an original training stimulus. A number of studies have shown that derived stimulus relations do in fact generalize to novel dimensional variants of training stimuli, thus making the number of stimuli that can potentially enter into a derived stimulus relation infinite (see Fields \& Reeve, 2001; Fields, Reeve, Adams, \& Verhave, 1991; see also Rehfeldt \& Hayes, 2000; Rehfeldt, 2003; Rehfeldt \& Root, in press). For example, if a training stimulus is a red square, some dimensional variants might include orange squares or red rectangles. The transfer of functions to stimuli physically similar to an existing class member has also been shown to generalize to physically similar stimuli (Fields, Adams, Buffington, Yang, \& Verhave, 1996). Generalization may explain the widespread prejudices that are formed against all members of an existing culture, despite the fact that a person has had experience with only one member of the culture. For example, many Americans' negative views towards al Qaeda and Osama bin Laden transferred to all persons of Middle Eastern descent. For some, these views 
might have been strongest towards men wearing white robes and who have long gray beards. For others, generalization on the basis of skin color may have been sufficient. An investigation might, for example, establish derived relations between cultural emblems, derogatory words or phrases, and abstract geometric figures. Having done this, we could then test the generalization of those relations to geometric figures similar along a dimension such as hue to the original figures. If many dimensional variants were now shown to have entered into a relation of sameness with the cultural emblems and the negative words, we would have a laboratory analogue of the generalization of prejudice.

Future research must not only focus upon the behavioral processes by which cultural stereotypes are established, but also the behavioral principles that may inspire effective interventions for reducing such stereotypes. An obvious step in this direction would be to attempt to alter the problematic derived stimulus relations and reestablish new networks that promote more favorable attitudes. A laboratory study might, for example, establish the stereotyped relations described previously, but then train the same cultural emblems to more positive words or phrases. We might examine how resilient to changes in the contingencies subjects' responding is, and consider whether direct punishment for the previously established stereotyped relations is necessary to eliminate them. Further intervention may be required for subjects to acquire the new relations. As previously noted, Burns (2001) and Leslie et al. (1993) explored the role of relaxation training on the ability of clinically-anxious patients to form verbal relations that would otherwise have been difficult or impossible. Laboratory experiments might also investigate the role that relaxation training might have on the readiness with which problematic verbal relations are destroyed and more adaptive verbal relations are established.

Wide scale investigations of clinical applications are also in order. Further demonstrations of the efficacy of the "mindfulness" approach, which was previously shown to be successful in changing attitudes towards persons with physical disabilities (Langer et al., 1985) are necessary. Its effectiveness in reducing prejudices towards persons of other cultures remains to be seen. Deliteralization is another clinical approach that awaits further research. For example, if individuals with prejudices towards Middle Easterners are to repeat negative terms over and over until the terms become meaningless, will subjects show reduced stereotypes on subsequent rating scale assessments? The effectiveness of community programs and practices should also be explored. As previously discussed, individuals acquire a history of relational responding on the basis of experience with exemplars. Many communities attempt to provide its citizens with such exemplars, albeit unsystematically. The effects of multicultural and heritage festivals on attitude change should be systematically explored.

In conclusion, we live in interesting times and great challenges lie ahead. With the advent of global terrorism it should now be clear that the war to be settled is not one based on laser-guided missiles and anthrax alone. Insofar as it is a war based on hatred and fear, it is to that extent also a psychological war (see Crenshaw, 2000). As psychologists we need to step up to the urgent challenge of 


\section{DIXON ET AL.}

using our technologies to reduce human suffering on an international scale and to avert any further terrorist atrocities. This endeavor must to some extent be played out on the political stage. What we hope to have demonstrated here, however, is that a scientific functional-analytic understanding of prejudice and hatred may also make a significant contribution to dealing with the changes we all now face. If this is to be a war on several fronts, then we must ensure that we make the war on prejudice be a briefly fought and bloodless one.

\section{REFERENCES}

Alper, G. (2002). Up close and personal: September 11, through the lens of a psychotherapist. Journal of Loss and Trauma, 7, 251-261. http://dx.doi.org/10.1080/10811440290057657

Barnes, D. (1994). Stimulus equivalence and relational frame theory. The Psychological Record, 44, 91-124.

Barnes-Holmes, D., \& Barnes-Holmes, Y. (2000). Explaining complex behavior: Two perspectives on the concept of generalized operant classes. The Psychological Record. $50,251-265$.

Barnes, D., \& Roche, B. (1996). Relational frame theory and stimulus equivalence are fundamentally different: A reply to Saunders. The Psychological Record, 46, 489508.

Burns, M. (2001). Stimulus equivalence, relaxation training and clinical anxiety. Unpublished Doctoral thesis, University of Ulster at Coleraine, Northern Ireland.

Clayton, T. M. (1995). Changing organizational culture through relational framing. Unpublished Master's thesis, University of Nevada, Reno.

Crenshaw, M. (2000). The psychology of terrorism: An agenda for the $21^{\text {st }}$ century. Political Psychology, 21, 405-420. http://dx.doi.org/10.1111/0162-895X.00195

Council on American-Islamic Relations (2002). The status of Muslim civil rights in the United States: Stereotypes and civil liberties. http://www.cair-net.org/civilrights2002/ civilrights2002.doc.

Deen, T. (2002, February 5). Rights: Discrimination against Muslims increases in US. Inter Press Service. Retrieved from http://www.oneworld.net/external/?url=http\%3A\%2F\%2Fwww.oneworld.org\%2Fips 2\%2Fjul98\%2F04_05_003.html

Desforges, D. M., Lord, C. G., Ramsey, S. L., Mason, J. A., Van Leeuwen, \& Lepper (1991). Effects of structured cooperative contact on changing negative attitudes toward stigmatized social groups. Journal of Personality and Social Psychology, 60, 531-544. http://dx.doi.org/10.1037/0022-3514.60.4.531

Dixon, M. R., Zlomke, K. M., \& Rehfeldt, R. A. (under review). Restoring Americans' Nonequivalent Frames of Terror. An Application of Relational Frame Theory.

Dixon, M. R., Rehfeldt, R. A., Zlomke, K. M. (under review). Exploring the development and dismantling of equivalence classes involving terrorist stimuli.

Dougher, M. J., Auguston, E. M. , Markham, M. R., Greenway, D. E., \& Wulfert, E. (1994). The transfer of respondent eliciting and extinction functions through stimulus equivalence classes. Journal of the Experimental Analysis of Behavior, 62, 331-351. http://dx.doi.org/10.1901/jeab.1994.62-331

Duggal, H. S., Berezkin, G. \& John, V. (2002). PTSD and TV viewing of the World Trade Center. Journal of the American Academy of Child and Adolescent Psychiatry, 41, 494-495. http://dx.doi.org/10.1097/00004583-200205000-00002 
Dymond, S., \& Barnes, D. (1995). A transformation of self-discrimination response functions in accordance with the arbitrarily applicable relations of sameness, morethan, and less-than. Journal of the Experimental Analysis of Behavior, 64, 163-184. http://dx.doi.org/10.1901/jeab.1995.64-163

Dymond, S. \& Rehfeldt, R. A. (2000). Understanding complex behavior: The transformation of stimulus functions. The Behavior Analyst, 23, 239-254.

Fazio, R. H. (2001). On the automatic activation of associated evaluations: An overview. Cognition and Emotion,15, 115-141. http://dx.doi.org/10.1080/02699930125908

Fields, L., Adams, B.J., Buffington, D.M., Yang, W., \& Verhave, T. (1996). Response transfer between stimuli in generalized equivalence classes: A model for the establishment of natural kind and fuzzy subordinate categories. The Psychological Record, 46, 665-684.

Fields, L., Adams, B.J., \& Verhave, T. (1993). The effects of equivalence class structure on test performances. The Psychological Record, 43, 697-712.

Fields, L., \& Reeve, K. F. (2001). A methodological integration of generalized equivalence classes, natural categories, and cross-modal perception. The Psychological Record, 51, 67-87.

Fields, L., Reeve, K.F., Adams, B.J., \& Verhave, T. (1991). Stimulus generalization and equivalence classes: A model for natural categories. Journal of the Experimental Analysis of Behavior, 55, 305-312. http://dx.doi.org/10.1901/jeab.1991.55-305

Hayes, S. C. \& Barnes, D. (1997). Analyzing derived stimulus relations requires more than the concept of stimulus class. Journal of the Experimental Analysis of Behavior, 68, 235-270. http://dx.doi.org/10.1901/jeab.1997.68-235

Hayes, S. C., Barnes-Holmes, D., \& Roche, B. (Eds.), (2001). Relational frame theory: A post-Skinnerian account of human language and cognition. New York: Plenum Press.

Hayes, S. C. \& Blackledge, J. T. (2001). Language and cognition: Constructing an alternative account within the behavioral tradition. In S. C. Hayes, D., BarnesHolmes, \& B. Roche (Eds.), Relational frame theory: A post-Skinnerian account of human language and cognition-(pp. 3-20). New York: Plenum Press.

Hayes S. C., Gifford, E. V., \& Ruckstuhl, Jr., L. E. (1996). Relational frame theory and executive function. Chapter in G.R. Lyon \& N. A. Krasnegor (Eds.), Attention, memory and executive function (pp.279-305). Baltimore: Brookes.

Hayes, S. C. (1992). Verbal relations, time, and suicide. In S.C. Hayes \& L. J. Hayes (Eds.), Understanding verbal relations (pp. 109-120). Reno, NV: Context Press.

Hayes, S.C., Strosahl, K., \& Wilson, K.G. (1999). Acceptance and commitment therapy: An experiential approach to behavior change. New York: Guilford.

Hayes, S.C., Niccolls, R., Masuda, A., \& Rye, A. (2002). Prejudice, terrorism and behavior therapy. Cognitive and Behavioral Practice, 9, 296-301. http://dx.doi.org/10.1016/S1077-7229(02)80023-2

Healy, O., Barnes-Holmes, D., \& Smeets, P. M. (2000). Derived relational responding as generalized operant behavior. Journal of the Experimental Analysis of Behavior, 74, 207-227. http://dx.doi.org/10.1901/jeab.2000.74-207

Kettl, P. \& Bixler, E. (2002). Changes in psychotropic drug use after September 11, Psychiatric Services, 53, 1475-1476. http://dx.doi.org/10.1176/appi.ps.53.11.1475-a

Langer, E. J., Bashner, R. S. \& Chanowitz, B. (1985). Decreasing prejudice by increasing discrimination. Journal of Personality and Social Psychology, 49, 113-120. http://dx.doi.org/10.1037/0022-3514.49.1.113 


\section{DIXON ET AL.}

Leslie, J.C., Tierney, K., Robinson, C. P., Keenan, M., Watt, A., \& Barnes, D. (1993). Differences between clinically anxious and non-anxious subjects in a stimulus equivalence training task involving threat words. The Psychological Record, 43, 153-162.

Lipkens, G., Hayes, S. C., \& Hayes, L. J. (1993). Longitudinal study of derived stimulus relations in an infant. Journal of Experimental Child Psychology, 56, 201-239. http://dx.doi.org/10.1006/jecp.1993.1032

LoPiccolo, J. (1994). Acceptance and broad spectrum treatment of paraphilias. In S.C. Hayes, N.S. Jacobson, V.M. Follette, \& M.J. Dougher (Eds.), Acceptance and change: Content and context in psychotherapy (pp. 149-170). Reno, NV: Context Press.

Macrae, C. N., Bodenhausen, G. V., Milne, A. B., \& Jetten, J. (1994). Out of mind but back in sight: Stereotypes on the rebound. Journal of Personality and Social Psychology, 67, 808-817. http://dx.doi.org/10.1037/0022-3514.67.5.808

O’Hora, D., Barnes-Holmes, D., \& Roche, B, \& Smeets, P. M. (in press). Derived relational networks and control by novel instructions: A possible model of generative verbal responding. The Psychological Record.

O’Hora, D., Roche, B., Barnes-Holmes, D. \& Smeets, P. (2002). Response latencies to multiple derived stimulus relations: Testing two predictions of Relational Frame Theory. The Psychological Record, 52, 51-75.

Pyszczynski, T., Solomon, S., \& Greenberg, J. (2003). In the wake of 9/11: The psychology of terror. Washington, DC: American Psychological Association.

Purdon, C. (1999). Thought suppression and psychopathology. Behaviour Research and Therapy, 37, 1029-1054. http://dx.doi.org/10.1016/S0005-7967(98)00200-9

Rehfeldt, R.A. (2003). Establishing contextual control over generalized equivalence relations. The Psychological Record, 53, 415-428

Rehfeldt, R.A., \& Hayes, L.J. (2000). The long-term retention of generalized equivalence classes. The Psychological Record, 50, 405-428.

Rehfeldt, R.A., \& Root, S. (in press) The Generalization and retention of equivalence relations in adults with mental retardation. The Psychological Record.

Rehfeldt, R.A., Latimore, D., \& Stromer, R. (2003). Observational learning and the formation of classes of reading skills by individuals with autism and other developmental disabilities. Research in Developmental Disabilities, 24, 333-358. http://dx.doi.org/10.1016/S0891-4222(03)00059-3

Roche, B., \& Barnes, D. (1996). Arbitrarily applicable relational responding and sexual categorization: A critical test of the derived difference relation. The Psychological Record, 46, 451-475.

Roche, B., \& Barnes, D. (1997). A transformation of respondently conditioned stimulus function in accordance with arbitrarily applicable relations. Journal of the Experimental Analysis of Behavior, 67, 275-301. http://dx.doi.org/10.1901/jeab.1997.67-275

Roche, B., Barnes-Holmes, D., Smeets, P. M., Barnes-Holmes, Y., \& McGeady, S. (2000). Contextual control over the derived transformation of discriminative and sexual arousal functions. The Psychological Record, 50, 267-291.

Roche, B., Barnes-Holmes, D., Barnes-Holmes, Y., \& Hayes, S. C. (2001). Social processes. In S. C. Hayes, D., Barnes-Holmes, \& B. Roche (Eds.), Relational frame theory: A post-Skinnerian account of human language and cognition. (pp. 197-209). New York: Plenum Press. 
Roche, B., Barnes-Holmes, Y., Barnes-Holmes, D., Stewart, I., \& O’Hora, D. (2002). Relational frame theory: A new paradigm for the analysis of social behavior. The Behavior Analyst, 25, 75-91.

Swarthyhuy (2002, April 7). Muslims in US face more discrimination after 9/11 \{Msg 1\}. Message posted to www.freerepublic.com/focus/news/675654/posts.

Sherif, M. (1961). Experiments in group conflict. Scientific American, 195, 54-58. http://dx.doi.org/10.1038/scientificamerican1156-54

Sherif, M., Harvey, O.J., White, J., Hood, William, \& Sherif, C. W. (1961). Intergroup conflict and cooperation: The Robbers Cave experiment. Norman, OK: UniversityBook Exchange.

Sidman, M., (1986). Functional analysis of emergent verbal classes, in T. Thompson \&M.E. Zeiler (Eds.), Analysis and Integration of Behavioral Units, (pp. 213-245).Hillsdale, NJ: Laurence Erlbaum Associates.

Smart, L., \& Wegner, D. M. (1999). Covering up what can't be seen: Concealable stigma and mental control. Journal of Personality and Social Psychology, 77, 474-486. http://dx.doi.org/10.1037/0022-3514.77.3.474

Staats, A.W., \& Staats, C. K. (1958). Attitudes established by classical conditioning. Journal of Abnormal and Social Psychology, 57, 87-40. http://dx.doi.org/10.1037/h0042782

Steele, D. L., and Hayes, S. C. (1991). Stimulus equivalence and arbitrarily applicable relational responding. Journal of the Experimental Analysis of Behavior, 56, 519-555. http://dx.doi.org/10.1901/jeab.1991.56-519

Taylor, M. (1988). The terrorist. London: Brasseys.

Thobaben, M. (2002). The aftermath of the terrorist attacks on September 11, 2001: Posttraumatic stress disorder. Home Health Care Management and Practice, 45, 398399. http://dx.doi.org/10.1177/1084822302014005016

Watt, A., Keenan, M., Barnes, D., \& Cairns, E. (1991). Social categorization and stimulus equivalence. The Psychological Record, 41, 33-50.

Wegner, D. M. (1994). White bears and other unwanted thoughts. New York: Guilford.

Wegner, D. M., Schneider, D. J., Carter, S., III, \& White, L. (1987). Paradoxical effects of thought suppression. Journal of Personality and Social Psychology, 53, 409-418. http://dx.doi.org/10.1037/0022-3514.53.1.5

Wilson, K. G., Hayes, S. C., Gregg, J. \& Zettle, R. D. ( 2001). Psychopathology and psychotherapy. In S. C. Hayes, D., Barnes-Holmes, \& B. Roche (Eds.), Relational frame theory: A post-Skinnerian account of human language and cognition. (pp. 211238). New York: Plenum Press. 